\title{
State of the Art Literature Survey 2015 on RFID
}

\author{
Salonie Vyas \\ B.E. Computer \\ Engineering student, \\ Sinhgad Academy of \\ Engineering, \\ Pune, Maharashtra, \\ India
}

\author{
Umang \\ Chaudhari \\ B.E. Computer \\ Engineering student, \\ Sinhgad Academy of \\ Engineering, \\ Pune, Maharashtra, \\ India
}

\author{
V. Chinmay \\ Nandini \\ B.E. Computer \\ Engineering student, \\ Sinhgad Academy of \\ Engineering, \\ Pune, Maharashtra, \\ India
}

\author{
Bhushan Thakare \\ Asst. Professor, \\ Sinhgad Academy of \\ Engineering, \\ Pune, Maharashtra, \\ India
}

\begin{abstract}
Since the announcement of the digital India perspective, the creation of smart cities is being planned. The traditional methods will not suitably apply to smart cities. Hence innovative methods need to be established for the same. The existing mechanisms will need suitable upgrades for use in smart cities. For example the access control which is widely manual will need upgrades for automation; similarly other areas will also need suitable changes in approach for the same.

RFID is one of the prominent technologies in the context of smart cities. It enables a range of applications for smart cities such as tracking of objects, localization, smart access control, healthcare applications etc.
\end{abstract}

\section{General Terms}

RFID, Antenna, Tag, Reader, Smart Groceries, Smart Cabinet, Smart Fridge, Access Control.

\section{Keywords}

RFID, RFID Antenna, RFID Tag, RFID Reader, Smart Appliances.

\section{INTRODUCTION}

A smart city is a city that functions in a sustainable and intelligent way by using digital technologies to enhance quality and performance of urban services, to ensure sustainability and efficiency.

Most of the people use automatic data capture technology that relies on radio-frequency without realizing it, like using a key to start a car or a card to access a room or validate entry. This technology is widely known as Radio-Frequency Identification or RFID. RFID is a promising technology and has a big potential to become ubiquitous in the near future. Objects also use this technology, as they are shipped from manufacture to storage and finally to the point of sale primarily for tracking the shipment.

The electronic chip of the RFID label contains information (or identification number) that can be read by the reader. This reader can also change the information contained by the label's memory. The content is application specific. It may be a unique identifier. Once this identifier has been written into the electronic circuit, it can no longer be modified, only read. (This principle is called WORM). Some electronic chips have another memory in which users can write, change and erase their own data. These memories range from a few bits to tens of kilobits ${ }^{[1]}$.

\section{HISTORY}

1940: RFID was used for the first time in World War II to identify planes. This was to identify friend or foe (allies or enemies) using the planes radar to read an identification number.

1970: From 1960 to 1970, RFID Systems were used secretively by the Army to control access into sensitive areas like nuclear plants etc.

1980: Passive tags were created with the advancement of the technology. With these it was no longer required for the energy to be embedded into the tags leading to a significant cost and maintenance reduction.

1990: Beginning of Standardization for the interoperability of RFID.

1999: The Auto-ID Centre specializing in Automatic Identification (including RFID) was established by MIT.

From 2005: RFID technologies are now extensively used in almost all industrial sectors (automotive, transport, statistics, health, aerospace etc.). ISO took part in initiating technical and applicative standards that led to a high degree of interoperability or interchangeability ${ }^{[1]}$.

\section{RFID}

Radio-frequency identification (RFID) is a wireless technology that uses electromagnetic waves (Radio) to transfer data for Automatic Identification and Object Tracking.

RFID is an automatic recognition method, relying on storing and remotely acquiring data using devices called RFID tags or transponders ${ }^{[2]}$. Interrogators or readers are two-way radio transmitter-receivers which send a signal to the tag and read its response. The technology requires some extent of collaboration between an RFID reader and an RFID tag.

A basic RFID system consists of three components:

- An antenna or coil

- A transceiver (Reader)

- A transponder (RF tag) 


\section{a) RFID antennas}

They provide the crucial link between reader and tag, serving as the channel that moves data back and forth ${ }^{[3]}$. The antenna emits radio signals that activate a tag; to read and write data to it. Antenna is a channel between the tag and the transceiver. It controls the system's data acquisition and communication.
An RFID reader transmits an encoded radio signal to verify the tag. The RFID tag after receiving the message responds with its identification and other data. Multiple types of RFID are available in the market classified by their frequency ranges:

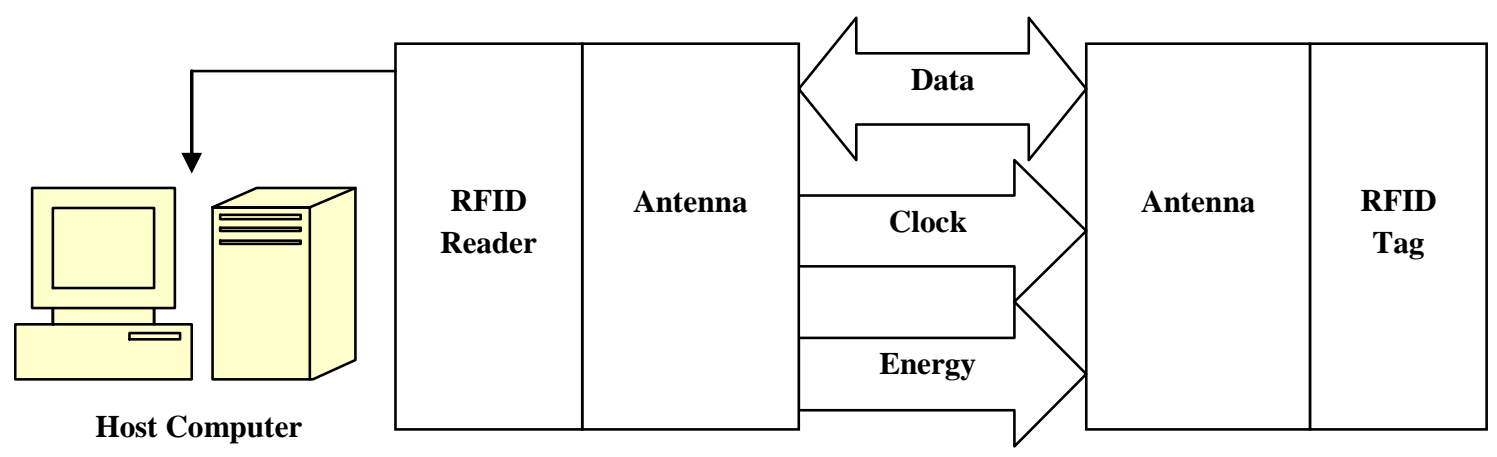

Fig. 1. RFID System Working

Antennas come in a variety of shapes and sizes; they can be built into variety of devices like a door frame to obtain tag data from persons or things passing through the door, or mounted on an expressway tollbooth to keep an eye on traffic passing by on a freeway. The EMF produced by an antenna is persistent when multiple tags are examined continually. If constant examination is not required, a sensor device can deactivate the field ${ }^{[4]}$

\section{b) RFID Transceiver}

An RFID transceiver is a device that transfers radio waves to RFID tags and collects the radio waves reflected or transmitted by the tags. It is also known as a reader or an interrogator ${ }^{[5]}$.

The RF transceiver may be enclosed within the same enclosure as the reader or it may be a separate part of equipment in which case it is called RF module. It controls and modulates the radio frequencies transmitted and received by the antenna. It filters and amplifies the backscatter signal from a passive RFID tag ${ }^{[4]}$

\section{c) RFID Tag (Transponder)}

An RFID tag is an object that can be attached to or integrated in a product, person or an animal for identification and tracking purpose using radio waves. The tags contain electronically stored information. Some tags can be read from several meters away and further than the line of sight of the reader. ${ }^{[2]}$

- $\quad$ RFID tags can be either passive, battery-assisted passive or Active. [6]

- An active tag has an on-board battery and periodically transmits its ID signal.

- A passive tag is a bit cheaper and smaller because it has no battery and the tag utilizes the radio energy transmitted by the reader.

- Tags can be read-only, which has a factory-assigned serial number that is used as a key into a database for Identification.

- Tags can also be read/write, where object-specific data can be written into the tag by the system user.
1) Low-frequency $(30 \mathrm{KHz}$ to $500 \mathrm{KHz})$

2) Mid-Frequency (900 KHz to $1500 \mathrm{MHz})$

3) High Frequency (2.4GHz to $2.5 \mathrm{GHz})$

From the above data it can be inferred that:

- $\quad$ RF range of low frequency tags ranges from $3 \mathrm{~m}$ to $5 \mathrm{~m}$ and cost of low-frequency system ranges to few hundred dollars.

- Mid-frequency tags ranges from $5 \mathrm{~m}$ to $17 \mathrm{~m}$.

- High frequency tags ranges from $5 \mathrm{ft}$ to $90 \mathrm{ft}$. The cost of high-frequency system ranges somewhere close to 5000 dollars.

- The RFID system is used in the following fields: Access Control, Promotion Tracking, Transportation, Advertising and Logistics, Public Transports for deducing travel Fare, Passports, Medicine and Health Care and Libraries.

\section{ADVANTAGES AND LIMITATIONS OF THE TECHNOLOGY}

\subsection{Advantages}

- Human intervention is not required in Tag detection which reduces employment costs and eliminates human errors from data collection

- Line-of-sight is not required hence Tag placement is less constrained.

- RFID tags have a longer read range as compared to barcodes.

- Unlike barcodes Tags can have read/write memory capability.

- An RFID tag can store large amounts of data and unique identifier.

- Tags are robust to unfavorable conditions (dust, chemicals, physical damage etc.).

- Multiple tags can be read simultaneously. 
- RFID tags can be combined with sensors.

- $\quad$ Automatic reading at several places decreases time lags and inaccuracies in an inventory,

- Tags can locally store supplementary information; such distributed data storage may increase fault forbearance of the whole system.

- $\quad$ Reduces inventory control and provisioning costs.

- $\quad$ Reduces warranty claim processing costs [7].

\subsection{Limitations ${ }^{[8]}$ :}

- Cost: Although an RFID tag can cost as less as a few cents and the cost has decreased over time, it still needs investment to install on a good, which doesn't pay off all the times. While an RFID tag is helpful for tagging and tracking, it is not economically feasible for tagging very low value goods. This is a particular problem with active tags (those that require a local power source), which can cost up to a dollar each.

- Signal Collision: It is not easy to read several RFID tags at the same time which leads to different signals from the tags interfering with one another. There are computerized methods for "detangling" such signals, but implementing and managing these methods increases operation costs.

- Standards: RFID does not have particularly powerful and fixed technical standards. Lack of standards is a problem when companies try to share RFID information and track with other organizations. Sources of possible differences include the speed at which data transmits and the methods that manage the signal collision.

- Frequencies: The wireless frequencies in use ranges across the three primary regions -- the America; Asia and Australia; and Europe and Africa. The variation in ranges restricts companies that want to utilize RFID tracking for International Inventory Management. "Crossover" frequencies work ubiquitously, but companies are required to plan ahead to use these types of frequencies when choosing tags and equipment [8].

\section{RFID Applications}

The use of RFID has been limited mainly for tracking and identification purposes only. Recently RFID has sparked a large business interest as a way of developing supply chain performance. Market activity has been in favor of RFID ever since Wal-Mart's 2003 claim that its top 100 suppliers must make use of RFID by January $2005^{[2]}$. The following are RFID applications ${ }^{[9]}$ :

- Manufacturing and Processing

- Inventory and Manufacture process monitoring.

- $\quad$ Storehouse order fulfillment.

- Supply Chain Management

- Inventory tracking systems.

- Logistics management.

- Retail

- Inventory control and customer insight.

- $\quad$ Auto checkout with reverse logistics.

- $\quad$ Security
- Access control.

- Counterfeiting and Burglary control/prevention.

- Location Tracking

- Traffic control and parking organization.

- Wildlife/Livestock monitoring and tracking ${ }^{[9]}$.

\subsection{Smart Groceries}

- $\quad$ Add an RFID tag to all items in the grocery.

- As the cart exits the store, it passes through an RFID transceiver.

- $\quad$ The cart is rung up in seconds [9].

\subsection{Smart Cabinet}

- Tagged item is taken from or placed in "Smart Cabinet"

- Smart Cabinet sporadically interrogates to assess inventory.

- Server/Database is updated to reflect item's position.

- Designated persons are notified about the items that need attention [9].

\subsection{Smart Fridge}

- Recognizes what's been put in it.

- Recognizes when things are removed.

- Creates automatic shopping lists.

- Notifies you when things are past their expiration.

- Shows you the recipes that match very much with what is available [9].

\subsection{Some More Smart Applications}

- "Smart" appliances:

- Closets that suggests on style depending on clothes available.

- Ovens that know recipes to cook prepackaged foodstuff.

- "Smart" products:

- Clothing, CDs, appliances, etc. tagged for store returns.

- "Smart" paper:

- Airline tickets that point to your location in the airport.

- "Smart" currency:

- Anti- counterfeiting and tracking ${ }^{[9]}$.

\subsection{Access Control}

- In Automated Toll System there is no need to stop the vehicle at toll plaza; it will just detect the RFID tag, which is mounted on vehicle. After identifying the RFID tag, the database on the administrators screen will appear and a specific amount of money from the customer's account will get deducted. So there will be no problem as in Manual Toll System. [10]

- By using RFID based automated toll collection system, the vehicle can check for security with the passing time, 
save the time for toll collection and reduce traffic congestion at the toll plaza. [11]

\section{CONCLUSION}

Thus it can be summarized that RFID technology has a big potential to become omnipresent in the near future. RFID is an excellent choice for identification applications wherein it is required to enforce authentication and applications such as supply chain management for tracking the produced items however there are certain implications that RFID causes which are monitored in this survey paper. Thus RFID can prove to be very useful in the future for smart applications and smart appliances. It will eventually lead the way for future technology development assistance and help in the development of smart cities.

\section{REFERENCES}

[1] CNRFID, from innovation to deployment of RFID and NFC Solution. Retrieved $2^{\text {nd }}$ October 2015. http://www.centrenational-rfid.com/introduction-to-therfid-article-15-gb-ruid-202.html

[2] RFID Based Vehicle Tracking System. Retrieved $12^{\text {th }} \quad$ October 2015. http://www.hbeonlabs.com/synopsis/RFID\%20PDF/RFI D\%20BASED\%20VEHICLE\%20TRACKING\%20SYS TEM.pdf

[3] RFID Antennas. Retrieved 15th October 2015. http://www.intermec.com/products/rfid/antennas/

[4] UMTS and Mobile Computing; Alexander Joseph Huber, Josef Franz Huber

[5] Global Positioning Systems: RFIDRetrieved $22^{\text {nd }}$ October2015. http://www.ehow.com/facts_7269050_transceiverrfid_.html

[6] Wikipedia Retrieved $2^{\text {nd }}$ October 2015. https://en.wikipedia.org/wiki/Radiofrequency_identification

[7] The RFID Technology and its Current Applications Retrieved $25^{\text {th }} \quad$ October 2015 http://www.ropardo.ro/fileadmin/prezentari_pdf/RFID_ MITIP2006.pdf

[8] International Journal of Computer and Electrical Engineering; December 2011; RFID Technology Principles, Advantages, Limitations \& Its Applications; Mandeep Kaur, Manjeet Sandhu, Neeraj Mohan and Parvinder S. Sandhu; Retrieved $2^{\text {nd }}$ November 2015

[9] RFID: Technology and Applications;Sridhar Iyer; IIT Bombay. October 2015.

Retrieved 18th

[10] Sachin Bhosale, "AUTOMATED TOLLPLAZA SYSTEM USING RFID”, ISSN: 2278-7798 International Journal of Science, Engineering and Technology Research (IJSETR) Volume 2, Issue 1, January $2013 . \quad$ Retrieved 18th October 2015.

[11] RFID Based Automated Toll Plaza System by AungMyint Win, Chaw MyatNwe, KyawZinLatt, International Journal of Scientific and Research Publications, Volume 4, Issue 6, June 2014. Retrieved $2^{\text {nd }}$ October 2015. 